\title{
A systematic review of the association between dietary patterns and health-related quality of life
}

\author{
Mahdi Vajdi ${ }^{1}$ and Mahdieh Abbasalizad Farhangi ${ }^{2^{*}}$ (])
}

\begin{abstract}
Background: Health related quality of life (HRQOL) is a potent indicator of individual's happiness and life satisfaction. The way in which the HRQOL is affected by the diet is a topic of constant interest and debate among researchers. Evaluating the association between single nutrients or foods and $\mathrm{HRQOL}$ fails to take into consideration the complex interactions between nutrients. Also, the findings from previous investigations on the relationship between dietary patterns and HRQOL have been inconsistent. Therefore, our aim was to assess the existing evidence regarding the relationship between the dietary patterns and HRQOL by conducting a systematic review.

Methods: A literature search was conducted in PubMed, Scopus, Web of Sciences and Google scholar databases from inception to March 2020, to identify studies that investigated associations between the dietary patterns (regardless of methods used to define dietary patterns) and HRQOL domains. Two researchers independently checked titles and abstracts, evaluated full-text studies, extracted data, and appraised their quality using the Newcastle-Ottawa Scale (NOS).

Results: Thirteen studies (four longitudinal, and nine cross-sectional studies), with a total of 43,445 subjects, were included. Of the studies included in this review, eight studies evaluated the association between "Mediterranean" dietary patterns (MDP) and $\mathrm{HRQOL}$, while five studies examined the association between different dietary patterns ("Healthy", "Unhealthy", "Western", "Fruit and vegetable", "Bread and butter" and etc.) and HRQOL. Excluding three studies which showed no significant association, healthy dietary patterns such as MDP, "Healthy" and "Fruit and vegetable" dietary patterns were associated with better HRQOL in physical and mental components scores. The quality assessment of included studies according to NOS criteria were ranged between medium to high quality.
\end{abstract}

Conclusion: According to the current evidence, "Healthy" dietary patterns and "Mediterranean" dietary patterns are associated with better dimension scores of HRQOL in both physical and mental summaries. While, unhealthy dietary patterns and "Western" dietary patterns are associated with lower scores of HRQOL. Further longitudinal studies are required to clarify the association between dietary patterns and HRQOL

Keywords: Health-related quality of life, Dietary patterns, Nutrition, Systematic review

*Correspondence: abbasalizad_m@yahoo.com

${ }^{2}$ Drug Applied Research Center, Tabriz University of Medical Sciences, Attar Neyshabouri Street, Tabriz, Iran

Full list of author information is available at the end of the article

\section{Introduction}

In recent years, life expectancy has increased in most countries, resulting in an increased prevalence of persons living with disabilities and chronic diseases $[1,2]$. The quality of life is a very complex concept and contains different psychological, physical, social, and cultural aspects of well-being and health-related original author(s) and the source, provide a link to the Creative Commons licence, and indicate if changes were made. The images or other third party material in this article are included in the article's Creative Commons licence, unless indicated otherwise in a credit line to the material. If material is not included in the article's Creative Commons licence and your intended use is not permitted by statutory regulation or exceeds the permitted use, you will need to obtain permission directly from the copyright holder. To view a copy of this licence, visit http://creativecommons.org/licenses/by/4.0/. The Creative Commons Public Domain Dedication waiver (http://creativeco mmons.org/publicdomain/zero/1.0/) applies to the data made available in this article, unless otherwise stated in a credit line to the data. 
quality of life (HRQOL) improvement is one of the most important aims of healthcare systems. HRQOL is a multidimensional concept, which subjectively measures an individual's social, emotional, functional and physical well-being [3]. HRQOL represents an individual's perception of how health affects a person's life quality and overall well-being and is measured with either specific questionnaires (e.g., Hospital Anxiety and Depression scale (HADS)) or generic one's (e.g., the 36-item Short Form (SF-36), the 12-item Short Form (SF-12)) [4].

Various factors, such as economic dependence [5], living situations [6], and lifestyle factors such as physical activity [7], and dietary habits [8,9] can affect HRQOL. Among them, healthy dietary habits play an important role in our state of mental and physical health and prevention and treatment of non-communicable diseases $[10,11]$. It is well established that an unhealthy diet can cause a reduction in physiological function and increasing the risk of disease development $[12,13]$, that there is a significant association between diet and alterations in immune and cognitive functions [14] and consequently that an improvement in diet is an important factor in the improvement of physiological function [15]. For instance, previous studies have shown that greater adherence to the "Mediterranean" diet (MED) is associated with a significant improvement in general psychological and physical health [4, 11]. In another study by Amarantos et al. [8], it has been highlighted that "Good nutrition improves HRQOL by promoting health, preventing dietary deficiency disease, and ameliorating or averting secondary malnutrition that is caused by or associated with other disease" (Amarantos, 2001, p.1).

Beyond single foods or nutrients, the assessment of whole dietary patterns is likely to provide a better explanation of diet-health relations. It is well established that people do not eat isolated nutrients and instead consume meals containing of a diversity of foods with complex combinations of nutrients that are likely to be interactive [16]. Whole-of-diet analysis represent a wider picture of a combination of foods and nutrients, such as the synergetic, additive, and antagonist effect of the foods [17] and provide researchers the opportunity to account for the interactions between different nutrients $[18,19]$. Thus, dietary patterns may be more predictive of HRQOL and disease risk than foods or nutrients in isolation. Dietary patterns are derived based on empirical approach using statistical methods including principal component analysis (PCA) or cluster analysis [16]. PCA create groups by intercorrelated dietary variables, while cluster analysis groups individuals into categories according to their reported mean consumptions of foods [20].
Few studies have examined the relationship between dietary patterns and HRQOL and their results are inconsistent and the majority of the studies in literature have been limited by cross-sectional study design. For example, studies by Mozzillo et al. [21], Holmes et al. [22] and Perez-Tasigchana et al. (UAM-cohort) [23] have not found any significant relationship between dietary patterns and HRQOL. However, some studies have reported the association of namely "Western" or "Unhealthy" dietary patterns with physical and mental chronic disease [24-26] and poor HRQOL [17, 27, 28]. Also, several studies reported that "Western" dietary pattern (increased intake of saturated fat and refined foods along with low intake of vegetable and fruits) is inversely associated with healthy factors such as immunity [29] and chronic diseases [30, 31]. While dietary patterns recognized in each study may be different from each other, some important characteristics of the healthy dietary pattern such as high intake of fruits, vegetables, legumes, seafood, whole grains, and low intake of refined grains, processed meat and sweetened foods have been suggested to be related to positive health benefits [32, 33]. Moreover, "Mediterranean" style dietary pattern (MEDP) is also associated with decreased risk of chronic disease and improved HRQOL [34-37]. This pattern particularly consists of the intake of nonrefined cereals and products, vegetables, fruits, olive oil and non-fat or low-fat dairy products is a known primary preventive tool against chronic cardiovascular events [38-40]. Numerous evidences have demonstrated that "Mediterranean" dietary pattern (MDP) reduces cardiovascular risk, improves survival from coronary heart disease (CHD), improved glycemic control and decreased risk of type 2 diabetes [41].Given the conflicting results and lack of systematically reviewed publication of earlier studies, the aim of this study was to systematically review published data to evaluate the relationship between dietary patterns and HRQOL among general population without age or disease restrictions.

\section{Methods}

\section{Search strategy}

A systematic search was conducted using Web of Sciences, Scopus, PubMed and Google scholar databases to the studies evaluated the relationship between dietary patterns and HRQOL from.

inception to March 2020. No language restriction was used. In search strategy, we used a combination of the MeSH (Medical Subject Headings) terms including the following: (Diet OR dietary OR patterns OR factor analysis OR cluster analysis OR principal component analysis OR diet patterns OR diet pattern OR 
dietary patterns OR dietary pattern OR eating pattern OR food patterns OR eating patterns OR food pattern OR patterns) AND (Life Quality OR Quality of Life OR Health-Related Quality of Life OR health status OR HRQOL OR QOL OR EQ-5D OR EuroQol 5 Dimensions OR SF-12 OR Short-form 12 OR SF-36 OR Short-form 36 OR life qualities OR questionnaire). Further explanations about the search strategy are provided in Table 1. Moreover, hand-searching from reference lists of potentially eligible studies, previous reviews was carried out to retrieve additional studies. The protocol of the present review has been registered in the International prospective register of systematic reviews (PROSPERO) and its registration number is CRD173914. Furthermore, the ethics committee of Tabriz University of Medical Sciences has approved the study's protocol (Registration number: IR.TBZMED. REC.1398.672).

\section{Inclusion criteria}

Studies were evaluated for eligibility using the inclusion and exclusion criteria in Table 2. The search results were uploaded into EndNote software (version X8, for Windows, Thomson Reuters, Philadelphia, PA, USA) and duplicates were removed. Therefore retrieved articles were merged and the review process has been facilitated. Two reviewers (MAF and MV) independently assessed the titles and abstracts of all studies identified in the search. Studies not meeting the eligibility criteria were eliminated. Furthermore, the reference lists of relevant reviews and of included articles were also checked for further studies. Full-texts of relevant articles were retrieved if meeting the eligibility criteria and findings

Table 1 Search strategy and number of publications in each electronic database

\begin{tabular}{|c|c|c|}
\hline Data base & Search strategy & $\begin{array}{l}\text { Number } \\
\text { of publications }\end{array}$ \\
\hline PubMed & $\begin{array}{l}\text { (Diet[Title/Abstract]) OR "Diet"[Mesh]) OR dietary[Title/Abstract]) OR patterns[Title/Abstract]) OR factor } \\
\text { analysis[Title/Abstract]) OR principal component analysis[Title/Abstract]) OR diet pattern[Title/Abstract]) OR } \\
\text { diet patterns[Title/Abstract]) OR dietary patterns[Title/Abstract]) OR dietary pattern[Title/Abstract]) OR eating } \\
\text { pattern[Title/Abstract]) OR eating patterns[Title/Abstract]) OR food pattern[Title/Abstract]) OR food patterns[Title/ } \\
\text { Abstract])) AND (Life Quality[Title/Abstract]) OR "Quality of Life"[Mesh]) OR Quality of Life[Title/Abstract]) OR } \\
\text { Health-Related Quality of Life[Title/Abstract]) OR HRQOL[Title/Abstract]) OR QOL[Title/Abstract]) OR EQ-5D[Title/ } \\
\text { Abstract]) OR EuroQol } 5 \text { Dimensions[Title/Abstract]) OR SF 12[Title/Abstract]) OR SF-36[Title/Abstract]) OR life } \\
\text { qualities[Title/Abstract]) OR questionnaire[Title/Abstract]) OR Short-form 36[Title/Abstract]) OR short form } \\
\text { 12[Title/Abstract]) }\end{array}$ & 390 \\
\hline Scopus & $\begin{array}{l}\text { ( ( TITLE-ABS-KEY ( "Diet ") OR TITLE-ABS-KEY ( "dietary patterns") OR TITLE-ABS-KEY ( "factor analysis ") OR TITLE- } \\
\text { ABS-KEY (" principal component analysis") OR TITLE-ABS-KEY ( "diet patterns ") OR TITLE-ABS-KEY ( "diet pattern ") } \\
\text { OR TITLE-ABS-KEY ( "dietary pattern") OR TITLE-ABS-KEY ( "eating patterns ") OR TITLE-ABS-KEY ( "eating pattern") } \\
\text { OR TITLE-ABS-KEY ( "food pattern") OR TITLE-ABS-KEY ("food patterns ") ORTITLE-ABS-KEY ( "food pattern") AND } \\
\text { ( ( TITLE-ABS-KEY ( "Life Quality ") OR TITLE-ABS-KEY ( "Quality of Life ") OR TITLE-ABS-KEY ( "Health-Related Quality } \\
\text { of Life ") OR TITLE-ABS-KEY ( "HRQOL ") OR TITLE-ABS-KEY ( "QOL ") OR TITLE-ABS-KEY ( "EQ-5D ") OR TITLE-ABS- } \\
\text { KEY ( "EuroQol } 5 \text { Dimensions ") OR TITLE-ABS-KEY ( "SF 12") OR TITLE-ABS-KEY ( "SF 36") OR TITLE-ABS-KEY ( life } \\
\text { qualities ") }\end{array}$ & 406 \\
\hline Web of science & $\begin{array}{l}\text { (("dietary patterns" OR "dietary patterns" OR "Diet" OR "diet pattern" OR "diet patterns" OR "eating patterns" OR } \\
\text { "eating patterns" OR "food pattern" OR "food pattern" OR "principal component analysis" OR " factor analysis ") } \\
\text { AND ( "Life Quality" OR " life qualities " OR "Quality of Life" OR "health related quality of life" OR "HRQOL" OR " QOL " } \\
\text { OR "EQ-5D "OR "EuroQol } 5 \text { Dimensions "OR "SF 12" OR "SF 36")) }\end{array}$ & 478 \\
\hline
\end{tabular}

Table 2 Inclusion and exclusion criteria for studies

\begin{tabular}{lc}
\hline Inclusion criteria & Exclusion criteria \\
\hline $\begin{array}{l}\text { Original human observational studies (cross-sectional, case control or cohort studies) } \\
\text { Studies assessing the relationship between dietary patterns and HRQOL in all age groups and } \\
\text { different disease }\end{array}$ & $\begin{array}{c}\text { Interventional studies, case series, systematic } \\
\text { review/ meta-analysis, case reports } \\
\text { Studies were included if they evaluated the HRQOL with a valid questionnaire including but not }\end{array}$ \\
$\begin{array}{l}\text { Simited to: SF-12, SF-36, WHOQOL, EORTC QLQ-C 30, PedsQL 3.0DM } \\
\text { instruments }\end{array}$ & - \\
Studies that examined whole diet (regardless of methods used to define dietary patterns) & Studies that examined single nutrients, single \\
foods, or single food groups
\end{tabular}


were re-screened. Any discrepancies were discussed between the two authors. The patient/Population; Intervention; Comparator; Outcome (PICO) question was as follows: in human models (P), does healthy dietary pattern (I) compared to unhealthy dietary pattern (C), affect HRQOL $(\mathrm{O})$ ?

\section{Data extraction}

Data extraction was conducted by two independent reviewers (MAF and MV), and any disagreements were resolved by consensus. The following data were extracted using a standard form: first author's name, study location, publication year, study design, sample size, age and gender of subjects, type of study population, dietary pattern assessment method, total number of participants and the number of case and controls, the HRQOL assessment tool and information about adjustments for possible confounders the main results.

\section{Quality assessment}

The methodological quality of included studies was evaluated using the Newcastle-Ottawa scale (NOS) adopted for cross-sectional and cohort studies. The 9-point NOS scale has scoring ranges from 0 to nine [42]. The tool assesses the studies based on three dimensionsselection, compatibility, exposure or outcome. Both authors rated the article independently and discussed the ratings.

\section{Results}

The current study follows the Preferred Reporting Items of Systematic Reviews and Meta-Analysis (PRISMA) guidelines for reporting the systematic reviews [43]. The flowchart of the study selection process is described in Fig. 1. A total of 1274 studies from four electronic databases and a further of five from hand searching were found. Removing 474 duplicates, 805 articles were

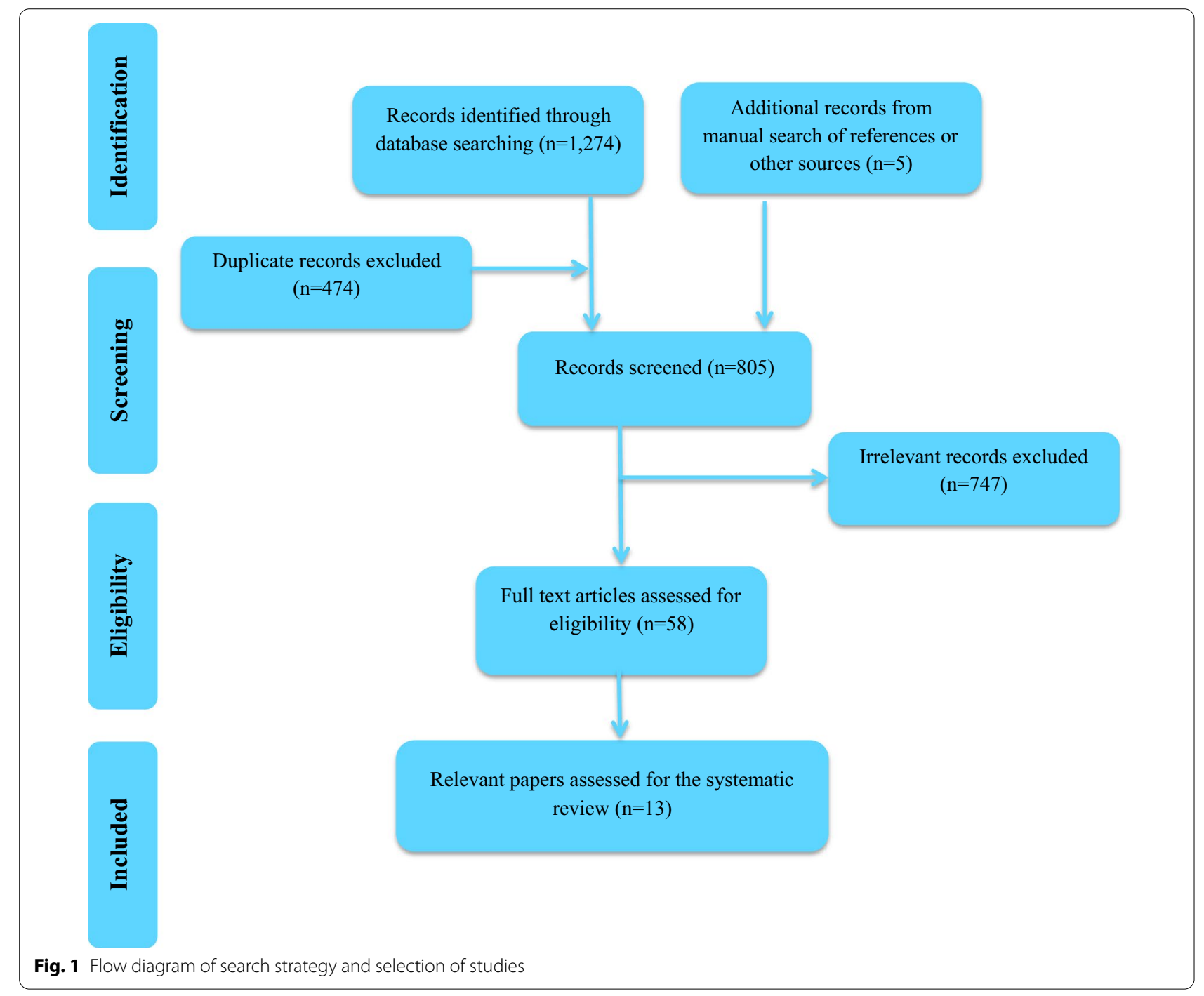


screened for title and abstract review and 58 articles were eligible for full text review. Finally, excluding 45 papers because of not meeting the inclusion criteria - not assessing the dietary pattern with either factor analysis or MDP method, not assessing the statistical associations between dietary patterns and HRQOL, design of intervention- a total of thirteen articles were included in the current systematic review.

The characteristics of included papers are presented in Table 3. Two longitudinal study [27, 44], two cohort studies analyzing the baseline characteristics $[23,28]$ and nine cross-sectional studies [17, 21, 22, 34-36, 45-47] were included. Studies were published between 2016 and 2019 and seven of these studies were carried out in Spain $[17,23,28,34,36,44,45]$, two in Italy $[21,35]$, one in France [22], one in USA [27], one in Australia [46] and one in Iran [47]. Studies where cross-sectional data were derived from longitudinal, cohort or even randomized trials were reported as cross-sectional. The largest sample size belonged to the study of Bonaccio et al. [35] considering 16,936 participants and the lowest samples size was belonged to the study of Gigic et al. [27] with 192 participants. The studies in the present review evaluated the relationship between dietary patterns evaluated with PCA or MDP score with HRQOL. We did not exclude disease status; accordingly five studies evaluated the dietary patterns with factor or cluster analysis $[17,22$, $27,28,47]$, while eight studies evaluate the MDP [21, 23, 34-36, 44-46]. Moreover, among all of the studies, one study was carried out among breast cancer survivals [17], one among subjects with intermediate cardiovascular risk [44], one in colorectal cancer [27], one in multiple sclerosis [47], one among patients with type 1 diabetes [21], one among patients with type 2 diabetes [34], one in patients with minor digestive symptoms [22] and others among general apparently healthy individuals. From the perspective of age, two studies were among older individual $[23,45]$ while others were performed among general population [17, 21, 22, 27, 28, 34-36, 44, 46, 47].

Major variability was observed between the HRQOL assessment tools. Five studies [23, 28, 35, 44-46] measured HRQOL with standard questionnaires of SF-36, SF-12 reporting physical components scores (PCS) and mental components scores (MCS) along with scores obtained for eight domains. Studies which carried out among cancer patients used the European Organization for Research and Treatment of Cancer Quality-of-life Questionnaire (EORTC QLQ) for measuring HRQOL $[17,27]$, one study used Food and Benefit Assessment (FBA) questionnaire [22], One study carried out among multiple sclerosis patients used Multiple Sclerosis Quality Of Life-54 questionnaire (MSQOL-54) [47], one study used Pediatric Quality of
Life Inventory 3.0 Diabetes Module (PedsQL 3.0 DM) (21), and one used Audit of Diabetes-Dependent Quality of Life (ADDQoL-19) [34]. Dietary assessment was also measured with variable tools. Most of the studies used food frequency questionnaires (FFQ) $[23,27,28,34,35$, 44-47], while one study evaluated dietary intake using three day non-consecutive food record [17], one study with non-consecutives $24 \mathrm{~h}$ recall method [22] and one with Traditional MDP score by 17-point questionnaire to assess adherence [23]. Among the studies evaluated MDP, one study evaluated traditional MDP score by 17 -point questionnaire [36], four studies [35, 44-46] measured MED score by Trichopoulou et al. [48], one study used the MED Quality Index (KIDMED) score [21], one study with three approaches of MDP index, prevention with MED (PREDIMED) score and Trichopoulou's MED score [23] and one with relative "Mediterranean" diet score (rMED) method [34].

The quality assessment of the included studies is presented in Table 4. The quality total score of studies ranged between 6 and 9 while most of them had medium and strong qualities scored by NOS scaling method. Based on our search of the literature, no prior study has assessed the relationship between other dietary patterns such as the Asian dietary patterns (traditional "Japanese" and "Chinese" diets and etc.), "Nordic", or "French" diets and HRQOL. In summary among thirteen included studies, ten studies found significant relations between dietary patterns (dietary patterns derived with factor or cluster analysis or MDP) and HRQOL while three studies did not observe any significant relations between dietary patterns and HRQOL [21-23]. Because of the great heterogeneity between the methodological approaches, study designs and report of results, the data synthesis and meta-analysis was not possible.

\section{Discussion \\ Principal findings}

In the current systematic review, the studies reporting the relationship between dietary patterns and HRQOL were reviewed. Most of the included studies showed the relationship between dietary patterns and HRQOL with only three exceptions showing no association in subjects with minor digestive problems and type 1 diabetes [21-23]. Of the studies evaluating the dietary patterns reported higher adherence to healthy dietary patterns are associated with better scores of HRQOL in one or more dimensions [17, 27, 28, 46, 47]. Also, higher adherence to MDP was associated with better scores of HRQOL [23, 34-36, 44, 45]. To our knowledge, this is the first systematic review to examine the effect of dietary patterns on HRQOL among general population without age or disease restrictions. 


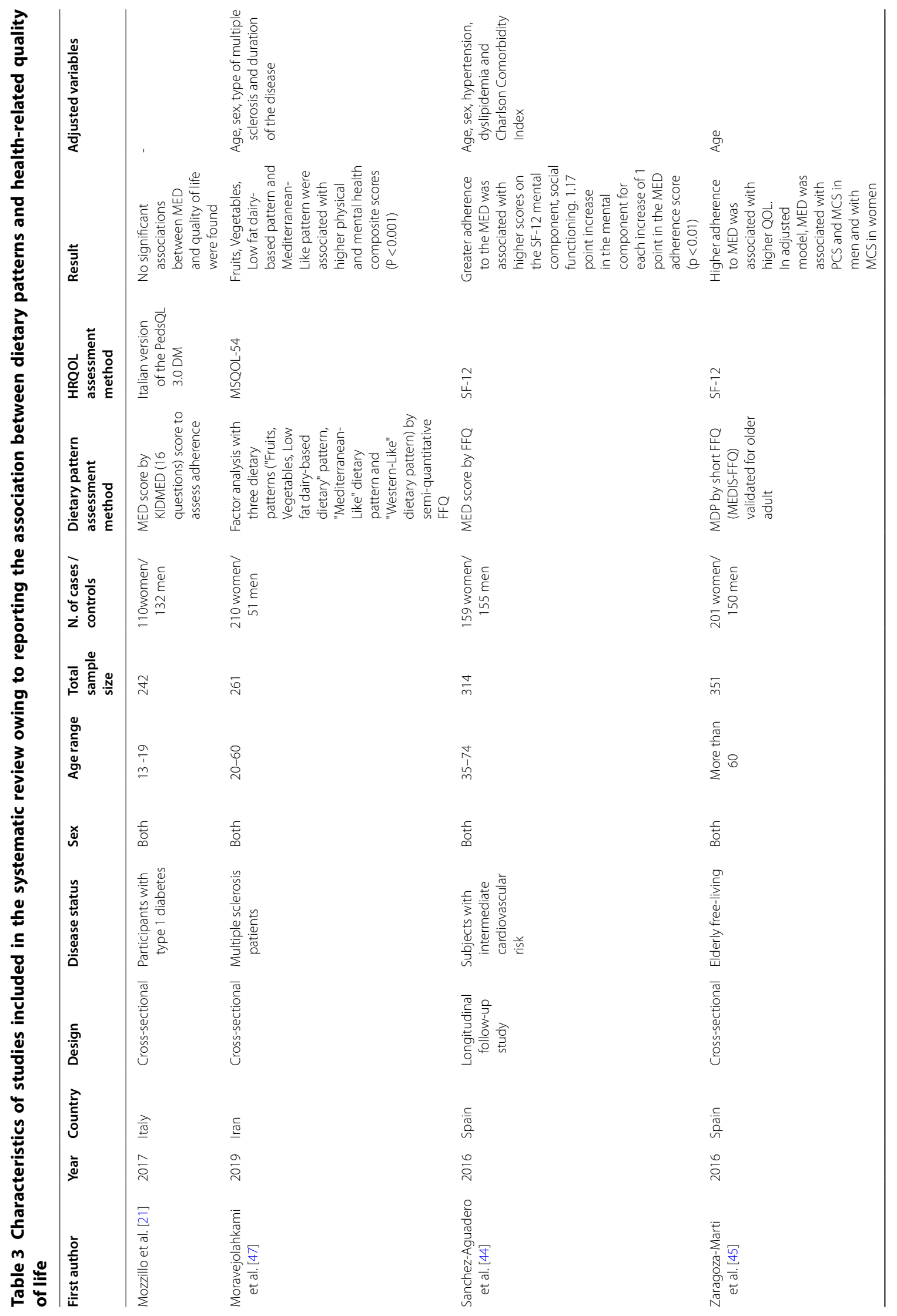




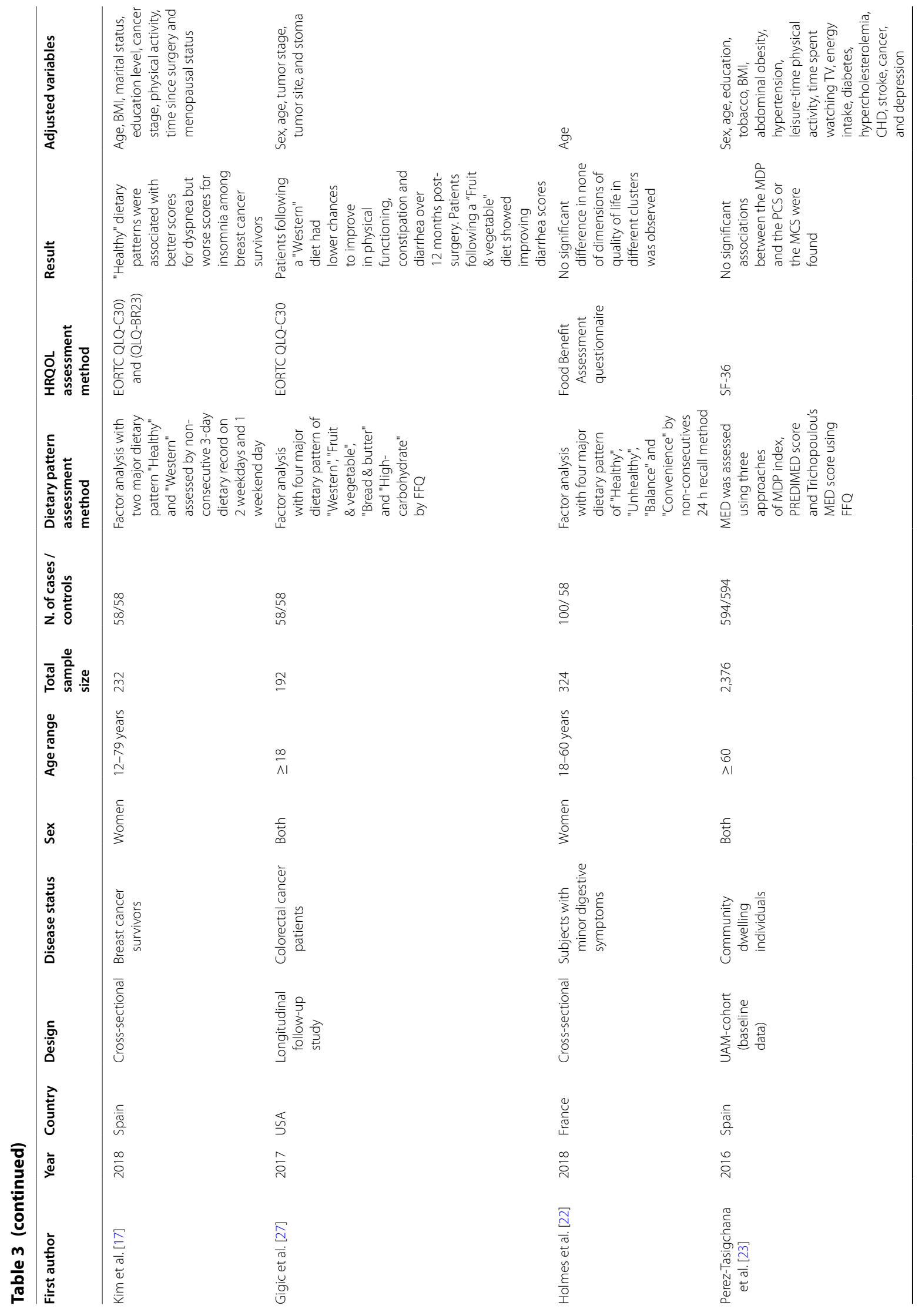




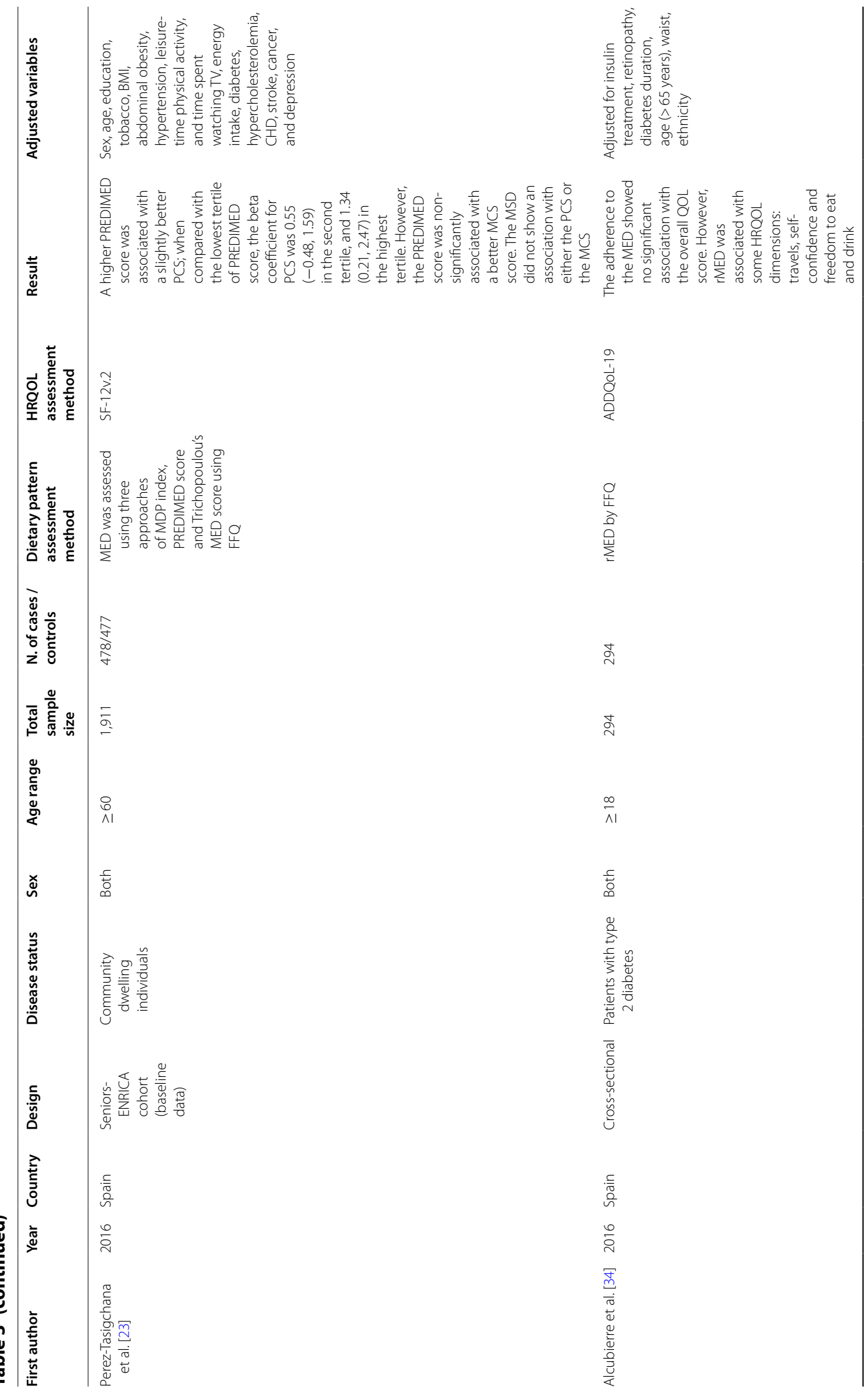




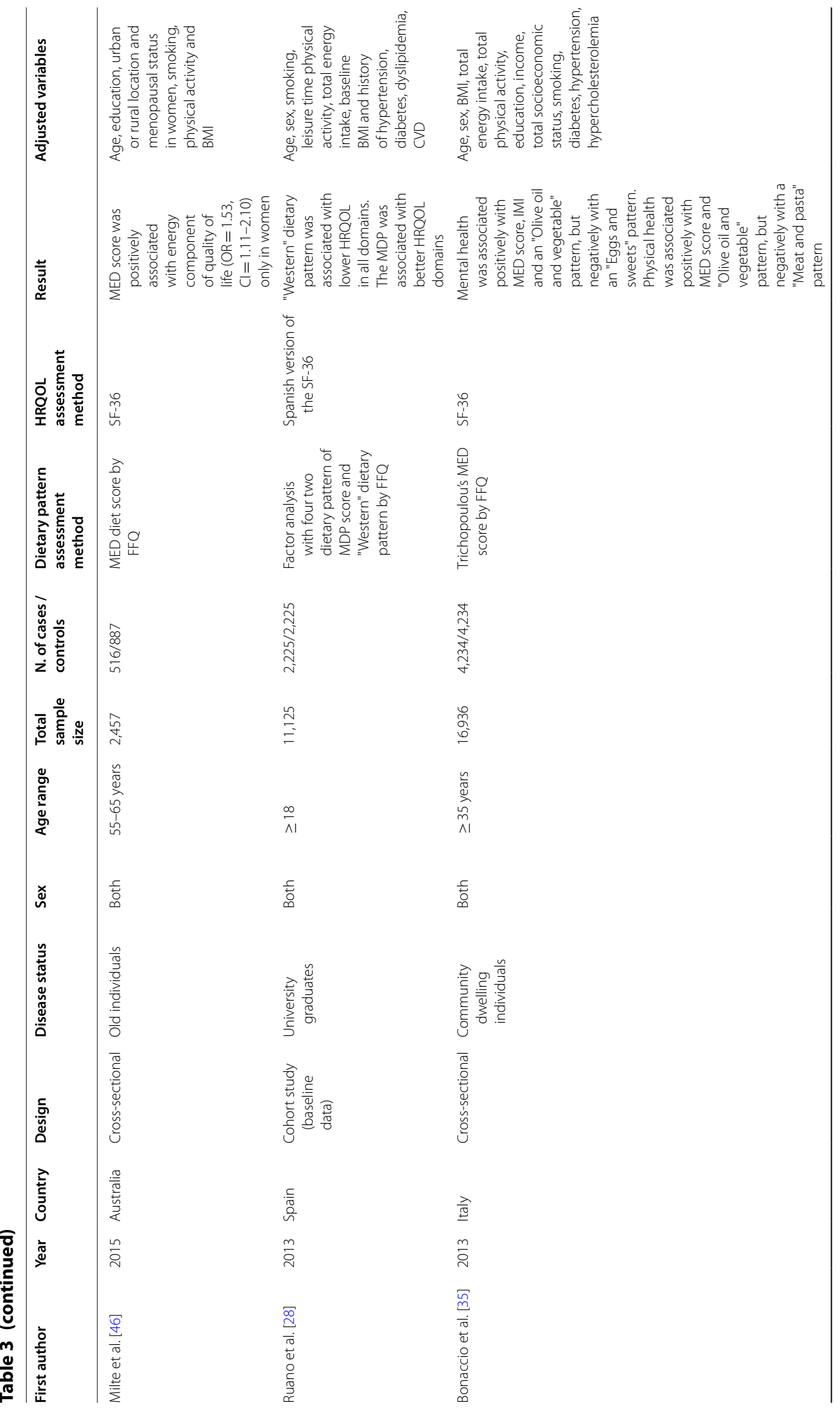




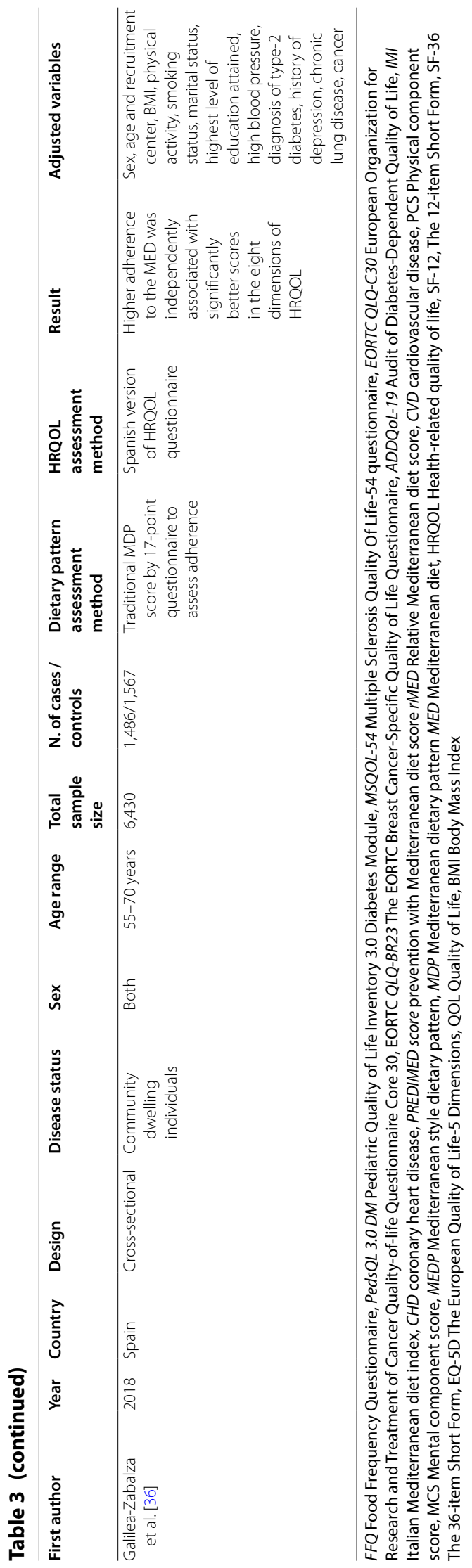


Table 4 Newcastle-Ottawa Quality Assessment Scale (NOS) for studies included in the systematic review

\begin{tabular}{|c|c|c|c|c|c|c|c|c|c|c|c|c|c|}
\hline \multirow[t]{2}{*}{ Author name } & \multirow{2}{*}{\multicolumn{2}{|c|}{ Study design }} & \multicolumn{6}{|c|}{ Selection } & \multirow{2}{*}{\multicolumn{2}{|c|}{ Comparability }} & \multicolumn{2}{|l|}{ Outcome } & \multirow[b]{2}{*}{$\begin{array}{l}\text { Final } \\
\text { score }\end{array}$} \\
\hline & & & \multicolumn{3}{|c|}{$\begin{array}{l}\text { Representativeness Sample size } \\
\text { of the sample }\end{array}$} & $\begin{array}{l}\text { Non- } \\
\text { respondents }\end{array}$ & \multicolumn{2}{|c|}{$\begin{array}{l}\text { Ascertainment } \\
\text { of the exposure }\end{array}$} & & & $\begin{array}{l}\text { Assessment } \\
\text { of the outcome }\end{array}$ & $\begin{array}{l}\text { Statistical } \\
\text { test }\end{array}$ & \\
\hline \multicolumn{2}{|l|}{$\begin{array}{l}\text { Galilea-Zabalza } \\
\text { et al. [36] }\end{array}$} & Cross-sectional & \multicolumn{2}{|l|}{ * } & - & * & * & & \multicolumn{2}{|l|}{ * } & $* *$ & * & 8 \\
\hline \multicolumn{2}{|l|}{$\begin{array}{l}\text { Bonaccio et al. } \\
\text { [35] }\end{array}$} & Cross-sectional & \multicolumn{2}{|l|}{$*$} & * & * & * & & \multicolumn{2}{|l|}{$* *$} & ** & * & 9 \\
\hline \multicolumn{2}{|l|}{ Milte et al. [46] } & Cross-sectional & \multicolumn{2}{|l|}{ * } & * & * & * & & \multicolumn{2}{|l|}{$* *$} & ** & * & 9 \\
\hline $\begin{array}{l}\text { Alcubierre et al } \\
{[34]}\end{array}$ & & Cross-sectional & * & & * & - & * & & $*$ & & ** & * & 7 \\
\hline Holmes et al. [2 & & Cross-sectional & * & & * & - & - & & * & & ** & * & 6 \\
\hline Kim et al. [17] & & Cross-sectional & * & & * & * & * & & $* *$ & & ** & * & 9 \\
\hline $\begin{array}{l}\text { Zaragoza-Marti } \\
\text { et al. [45] }\end{array}$ & & Cross-sectional & * & & * & - & * & & $*$ & & * & * & 6 \\
\hline $\begin{array}{l}\text { Moravejolahkar } \\
\text { et al. [47] }\end{array}$ & & Cross-sectional & $*$ & & * & * & * & & $* *$ & & ** & * & 9 \\
\hline Mozzillo et al. [? & [21] $\mathrm{Cl}$ & Cross-sectional & * & & * & * & * & & $* *$ & & $* *$ & * & 9 \\
\hline Author & Study & y Selection & & & & & & Compara & bility & Outcome & & & \\
\hline & & $\begin{array}{l}\text { Represent } \\
\text { of the expc } \\
\text { cohort }\end{array}$ & $\begin{array}{l}\text { ativeness } \\
\text { osed }\end{array}$ & $\begin{array}{l}\text { s Selection } \\
\text { of the non- } \\
\text { exposed } \\
\text { cohort }\end{array}$ & $\begin{array}{l}\text { Ascertainment } \\
\text { of exposure }\end{array}$ & $\begin{array}{l}\text { Demonstr } \\
\text { that outcc } \\
\text { of interest } \\
\text { was not p } \\
\text { at start of }\end{array}$ & $\begin{array}{l}\text { ation } \\
\text { me } \\
\text { resent } \\
\text { study }\end{array}$ & & & $\begin{array}{l}\text { Assessment } \\
\text { of outcome }\end{array}$ & $\begin{array}{ll}\text { Was } \\
\text { follow-up } \\
\text { long enough } \\
\text { for outcomes } \\
\text { to occur }\end{array}$ & $\begin{array}{l}\text { Adequacy } \\
\text { of follow } \\
\text { up of } \\
\text { cohorts }\end{array}$ & $\begin{array}{l}\text { Final } \\
\text { score }\end{array}$ \\
\hline $\begin{array}{l}\text { Ruano et al. } \\
\text { [28] }\end{array}$ & Cohort & ort * & & * & * & * & & $* *$ & & * & * & * & 9 \\
\hline $\begin{array}{l}\text { Perez- } \\
\text { Tasigchana } \\
\text { et al. [23] }\end{array}$ & Cohort & ort * & & * & * & $*$ & & $* *$ & & * & * & * & 9 \\
\hline $\begin{array}{l}\text { Perez- } \\
\text { Tasigchana } \\
\text { et al. [23] }\end{array}$ & Cohort & ort $*$ & & * & * & * & & $* *$ & & * & * & * & 9 \\
\hline $\begin{array}{l}\text { Gigic et al. } \\
\text { [27] }\end{array}$ & $\begin{array}{l}\text { Longi- } \\
\text { tudi- } \\
\text { nal }\end{array}$ & $\begin{array}{ll}\text { ji- } & * \\
\text { di- } & \\
\text { | }\end{array}$ & & * & * & * & & $* *$ & & * & * & * & 9 \\
\hline $\begin{array}{l}\text { Sanchez- } \\
\text { Aguadero } \\
\text { et al. [44] }\end{array}$ & $\begin{array}{l}\text { Longi- } \\
\text { tudi- } \\
\text { nal }\end{array}$ & $\begin{array}{ll}\text { ji- } & \text { * } \\
\text { di- } & \\
\text { i }\end{array}$ & & * & * & * & & $* *$ & & * & * & * & 9 \\
\hline
\end{tabular}

One star represents a score of 1, and a study can be awarded a maximum score of 9 in total. The items were scored "*"if the answer was "YES," and "- "if the answer was "NO" or "UNCLEAR." The final quality scores were as follows: low quality $=0-3$; moderate quality $=4-6$; high quality $\geq 7$

\section{Details from previous research/studies}

To date, only one systematic review has been carried out to investigate the relationship of dietary patterns and quality of life in older people [4]. Like our results, they revealed that healthy dietary patterns were related to better quality of life in one or more domains and adherence to MED were significantly related to improvement in at least one of the quality of life domains. In another study by Ruano et al. [28] evaluating the baseline data of the SUN cohort, two major dietary patterns of the "Western" dietary pattern (rich in processed pastries and red meats) and the MDP (high in olive oil, vegetables and fruits) was identified among 11,128 participants. The "Western" dietary pattern was inversely associated with all domains of HRQOL. The magnitude of these differences between the participants in the highest versus lowest quintile of adherence to the "Western" dietary pattern ranged from 20.8 (for mental health) to 23.5 (for vitality). In opposite, the MDP was associated with better HRQOL domains while scores ranged from +1.3 (for physical functioning) to +3.4 (for vitality). In the study by Kim et al. [17] and Gigic et al. [27] among patients with colorectal and breast cancer, patients with higher adherence to "Western" diet had lower chances to improve in physical functioning, diarrhea and constipation. While, patients following a "Fruit and vegetable" and "Healthy" diet indicated improving diarrhea and dyspnea scores.

The deleterious effects of "Western" dietary patterns have been widely mentioned in numerous studies; its association with metabolic syndrome, obesity, insulin resistance [49], and risk of cardiovascular disease [50, 51]. Moreover, considering the relationship between 
"Western" dietary pattern and mental component summary of HRQOL, some studies reported an inverse relationship between "Western" dietary pattern and depression, anxiety [52], mental [53] and cognitive disorders [54]. One possible explanation is that high in saturated and trans fats, refined sugars, red and processed meat could reduce the brain derived neurotropic factor (BDNF) concentrations and to inhibit its expression via several pro-inflammatory cytokine production $[55,56]$.

In the study of Moravejolahkami et al. [47], examining the association between dietary patterns and HRQOL among 261 multiple sclerosis patients, results showed that "Fruits, vegetables, low fat dairy-based" pattern and "Mediterranean-Like" dietary pattern were associated with higher physical and mental health composite scores (P adjusted $<0.001$ ). In another study by Sanchez-Aguadero et al. [44], greater adherence to the MED was related to higher scores on the SF-12 social functioning and mental component. After adjustment for confounders, for each point of increase in the MED adherence score, there was an increase of 1.17 points in the mental component value $(\mathrm{p}<0.01)$. It is well documented that MDP is potentially able to protect against numerous chronic disease including cardiovascular events [57, 58] metabolic syndrome [59] and diabetes [60]. Also, from mental component summary point of view, MED could potentially decrease the risk of depression [61] cognitive decline and dementia $[62,63]$. Higher consumption of vegetables and fruits as a characteristic of MDP is associated with improved HRQOL [64]. Therefore, it is not out of expected that MED is related to improve in both mental and physical domain of HRQOL.

In addition, less than $25 \%$ of the studies ( 3 out of 13 studies) included in this review reported no significant association between dietary patterns and HRQOL. Mozzillo et al. [21] fails to show any significant relationship between adherence to the MED and HRQOL, maybe due to the low number of patients with poor diet quality in their study. Perez-Tasigchana et al. [23] found that PREDIMED scores were related to a marginally better PCS in the Seniors-ENRICA cohort and also reported no association between MED score and any of the HRQOL domains in the UAM-cohort. The studies were performed 10 years apart and both the studies used different methods to measure dietary pattern and HRQOL, and found consistent findings. In a cross sectional study by Holmes et al. [22]; it was noted that no significant differences in HRQOL were found between dietary patterns. They used cluster analysis to derive dietary patterns and FBA questionnaire for assessment of HRQOL.

\section{Summary}

There is an obvious fact that existing studies on dietary patterns focus mainly on MED or "Western" dietary patterns, and very little attention has been given to the effect of the other dietary patterns such as the "Japanese", "Nordic", "French", or "Chinese" traditional diet on HRQOL and more studies are required on these neglected dietary patterns. Accordingly, our study focuses more on MDP and "Western" dietary patterns. The "Nordic" diet is characterized by high intake of root vegetables, grains, berries, nuts, and seafood. The "Nordic" diet is similar to the MED but the "Nordic" diet emphasizes canola oil more than olive oil [65]. A recent cross-sectional study showed that high adherence to the "Nordic" diet was associated with a healthier lifestyle [66]. Side dishes in "Japanese" traditional diet include several species of fish that are a rich source of high quality protein as well as omega-3 acids, which are believed to be beneficial for human health [67].

As reported in the current review, most of the studies regarding the associations between dietary patterns and HRQOL were considered the healthy benefits of MDP in improvement of quality of life. Although there was a great heterogeneity in estimating the MED score, however, almost all of the studies had consistent results reporting the positive effects of the MED on HRQOL. In spite of observed associations between HRQOL and dietary patterns, the possible underlying mechanisms are unclear. In fact, all of the life domains including personal satisfaction, social interactions or economical characteristics could have direct relationships with food behaviors and eating ways and, together with the physical and mental health, could explain what we consider to be a good or poor quality of life [68].

\section{Strengths and limitations}

The current broad systematic review was performed according to PRISMA guidelines and was included all of the studies up to March 2020 in its literature search. We combined the studies in numerous disease and age groups because of the limited number of studies. Moreover, the included studies were large observational studies with cross-sectional design and therefore the causal inference could not be relied. Additionally, the dietary assessments and quality of life were both assessed by self-reported tools and might be a source of bias. Lastly, it will be better to develop a nutrition-specific quality of life assessment tool to better interpretation of the results of the effects of diet on the quality of life. The dietary assessment, quality of life measurements and data visualization varied 
from one study to another and the great heterogeneity among included studies regarding the design, dietary assessment, quality of life assessment tools and statistics made us unable to run a meta-analysis.

\section{Conclusion}

In conclusion, according to our findings, MDP and "Healthy" dietary patterns are associated with better dimension scores of HRQOL in both physical and mental summaries. While, "Unhealthy" dietary patterns and "Western" dietary patterns are associated with lower scores of HRQOL. Adjusting for the potential confounders, the results might be identifiable for final causal inference. Because of the great heterogeneity between the methodological approaches, designs and report of results, the meta-analysis was not possible. Further longitudinal studies are required to clarify the association between dietary patterns and HRQOL.

\begin{abstract}
Abbreviations
ADDQoL-19: Audit of Diabetes-Dependent Quality of Life; EQ-5D: The European Quality of Life-5 Dimensions; FFQ: Food Frequency Questionnaire; HRQOL: Health-related quality of life; KDQOL-36: Kidney Disease Quality of Life 36-item survey; MANSA: The Manchester Short Appraisal was used to assess self-rated quality of life; MCS: Mental component score; MDP: Mediterranean dietary pattern; MED: Mediterranean diet; MeSH: Medical subject headings; MSQOL-54: Multiple Sclerosis Quality of Life-54 questionnaire; NOS: The Newcastle-Ottawa Scale; PCS: Physical component score; PedsQL 3.0 DM: Pediatric Quality of Life Inventory 3.0 Diabetes Module; PREDIMED: Score prevention with Mediterranean diet score; rMED: Relative Mediterranean diet score; SF-12: The 12-item Short Form; SF-36: The 36-item Short Form.
\end{abstract}

\section{Acknowledgements}

Not applicable.

\section{Authors' contributions}

All authors have read and approved the manuscript; MAF was the main researcher, wrote the manuscript and supervised the project. MAF and MV were involved in data collection. MV was also involved in manuscript writing and revision.

\section{Funding}

This research has received no grant.

\section{Availability of data and materials} Not applicable.

\section{Ethics approval and consent to participate}

The current work has been approved by the ethics committee of the Tabriz University of Medical Sciences. (Identifier: IR.TBZMED.REC.1398.672).

\section{Consent for publication}

Not applicable.

\section{Competing interests}

The authors declare that there is no conflict of interest.

\section{Author details}

${ }^{1}$ Research Center for Evidence Based Medicine, Health Management and Safety Promotion Research Institute, Tabriz University of Medical Sciences, Tabriz, Iran. ${ }^{2}$ Drug Applied Research Center, Tabriz University of Medical Sciences, Attar Neyshabouri Street, Tabriz, Iran.
Received: 3 December 2018 Accepted: 24 September 2020

Published online: 12 October 2020

\section{References}

1. Roth GA, Abate D, Abate KH, Abay SM, Abbafati C, Abbasi N, et al. Global, regional, and national age-sex-specific mortality for 282 causes of death in 195 countries and territories, 1980-2017: a systematic analysis for the Global Burden of Disease Study 2017. Lancet. 2018;392(10159):1736-88.

2. James $\mathrm{SL}$, Abate $\mathrm{D}$, Abate KH, Abay SM, Abbafati C, Abbasi N, et al. Global, regional, and national incidence, prevalence, and years lived with disability for 354 diseases and injuries for 195 countries and territories, 1990-2017: a systematic analysis for the Global Burden of Disease Study 2017. Lancet. 2018;392(10159):1789-858.

3. Baumann C, Erpelding M-L, Perret-Guillaume C, Gautier A, Régat S, Collin $J-F$, et al. Health-related quality of life in French adolescents and adults: norms for the DUKE Health Profile. BMC Public Health. 2011;11(1):401.

4. Govindaraju T, Sahle BW, McCaffrey TA, McNeil JJ, Owen AJ. Dietary patterns and quality of life in older adults: a systematic review. Nutrients. 2018;10(8):971.

5. Tajvar M, Arab M, Montazeri A. Determinants of health-related quality of life in elderly in Tehran. Iran BMC Public Health. 2008;8(1):323.

6. Addington-Hall J, Kalra L. Who should measure quality of life? BMJ. 2001;322(7299):1417-20

7. Bize R, Johnson JA, Plotnikoff RC. Physical activity level and health-related quality of life in the general adult population: a systematic review. Prev Med. 2007:45(6):401-15.

8. Amarantos E, Martinez A, Dwyer J. Nutrition and quality of life in older adults. J Gerontol A Biol Sci Med Sci. 2001;56(suppl-2):54-64.

9. Farhangi MA, Dehghan $P$, Jahangiry L. Mental health problems in relation to eating behavior patterns, nutrient intakes and health related quality of life among Iranian female adolescents. PLoS ONE. 2018;13(4):e0195669.

10. Baldew S-SM, Krishnadath IS, Smits CC, Toelsie JR, Vanhees L, Cornelissen V. Self-reported physical activity behavior of a multi-ethnic adult population within the urban and rural setting in Suriname. BMC Public Health. 2015;15(1):485

11. Ruano-Rodríguez C, Serra-Majem L, Dubois D. Assessing the impact of dietary habits on health-related quality of life requires contextual measurement tools. Front Pharmacol. 2015;6:101.

12. Rantanen T, Harris T, Leveille SG, Visser M, Foley D, Masaki K, et al. Muscle strength and body mass index as long-term predictors of mortality in initially healthy men. J Gerontol A Biol Sci Med Sci. 2000;55(3):M168-M173173.

13. Cabioglu N, Bilgic S, Deniz G, Aktas E, Seyhun Y, Turna A, et al. Decreased cytokine expression in peripheral blood leukocytes of patients with severe sepsis. Arch Surg. 2002;137(9):1037-43.

14. Pearson J, Schlettwein-Gsell D, Brzozowska A, Van Staveren W, Bjornsbo K. Life style characteristics associated with nutritional risk in elderly subjects aged 80-85 years. J Nutr Health Aging. 2001;5(4):278-83.

15. Magri F, Borza A, del Vecchio S, Chytiris S, Cuzzoni G, Busconi L, et al Nutritional assessment of demented patients: a descriptive study. Aging Clin Exp Res. 2003;15(2):148-53.

16. Hu FB. Dietary pattern analysis: a new direction in nutritional epidemiology. Curr Opin Lipidol. 2002;13(1):3-9.

17. Kim N-H, Song S, Jung S-Y, Lee E, Kim Z, Moon H-G, et al. Dietary pattern and health-related quality of life among breast cancer survivors. BMC Women's Health. 2018;18(1):65.

18. McNaughton SA. Dietary patterns and diet quality: approaches to assessing complex exposures in nutrition. Aust Epidemiol. 2010;17(1):35.

19. Tucker KL. Dietary patterns, approaches, and multicultural perspective. Appl Physiol Nutr Metab. 2010;35(2):211-8.

20. Newby PK, Tucker KL. Empirically derived eating patterns using factor or cluster analysis: a review. Nutr rev. 2004:62(5):177-203.

21. Mozzillo E, Zito E, Maffeis C, De Nitto E, Maltoni G, Marigliano M, et al. Unhealthy lifestyle habits and diabetes-specific health-related quality of life in youths with type 1 diabetes. Acta Diabetol. 2017;54(12):1073-80.

22. Holmes BA, Habi-Rachedi F, Trotin B, Paineau D, Guyonnet D, Rondeau $P$, et al. Dietary patterns, digestive symptoms, and health-related quality 
of life in women reporting minor digestive symptoms. Nutrition. 2017;35:1328.

23. Perez-Tasigchana RF, Leon-Munoz LM, Lopez-Garcia E, Banegas JR, Rodriguez-Artalejo F, Guallar-Castillon P. Mediterranean diet and healthrelated quality of life in two cohorts of community-dwelling older adults. PLoS ONE. 2016;11(3):e0151596.

24. Baxter AJ, Coyne T, McClintock C. Dietary patterns and metabolic syndrome-a review of epidemiologic evidence. Asia Pac J Clin Nutr. 2006;15(2):134-42.

25. Li Y, Lv M-R, Wei Y-J, Sun L, Zhang J-X, Zhang H-G, et al. Dietary patterns and depression risk: a meta-analysis. Psychiatry Res. 2017;253:373-82.

26. Williams C, Lovegrove J, Griffin B. Dietary patterns and cardiovascular disease. Proc Nutr Soc. 2013;72(4):407-11.

27. Gigic B, Boeing H, Toth R, Bohm J, Habermann N, Scherer D, et al. Associations between dietary patterns and longitudinal quality of life changes in colorectal cancer patients: the ColoCare study. Nutr Cancer. 2018;70(1):51-60

28. Ruano C, Henriquez P, Martínez-González MÁ, Bes-Rastrollo M, Ruiz-Canela M, Sánchez-Villegas A. Empirically derived dietary patterns and health-related quality of life in the SUN project. PLOS ONE. 2013;8(5):e61490.

29. Myles IA. Fast food fever: reviewing the impacts of the Western diet on immunity. Nut J. 2014;13:61.

30. Danaei G, Singh GM, Paciorek CJ, Lin JK, Cowan MJ, Finucane MM, et al. The global cardiovascular risk transition: associations of four metabolic risk factors with national income, urbanization, and Western diet in 1980 and 2008. Circulation. 2013:127(14):1493-502.

31. Slattery ML, Potter JD, Ma KN, Caan BJ, Leppert M, Samowitz W. Western diet, family history of colorectal cancer, NAT2, GSTM-1 and risk of colon cancer. Cancer Causes Control. 2000;11(1):1-8.

32. Adriano LS, Sampaio HA, Arruda SP, Portela CL, de Melo MLP, Carioca AA, et al. Healthy dietary pattern is inversely associated with non-alcoholic fatty liver disease in elderly. Br J Nutr. 2016;115(12):2189-95.

33. Asghari G, Yuzbashian E, Mirmiran P, Hooshmand F, Najafi R, Azizi F. Dietary approaches to stop hypertension (DASH) dietary pattern is associated with reduced incidence of metabolic syndrome in children and adolescents. J Pediatr. 2016;174:178-84.

34. Alcubierre N, Martinez-Alonso M, Valls J, Rubinat E, Traveset A, Hernandez $M$, et al. Relationship of the adherence to the Mediterranean diet with health-related quality of life and treatment satisfaction in patients with type 2 diabetes mellitus: a post-hoc analysis of a cross-sectional study. Health Qual Life Outcomes. 2016:14(1):1-6.

35. Bonaccio M, Di Castelnuovo A, Bonanni A, Costanzo S, De Lucia F, Pounis $\mathrm{G}$, et al. Adherence to a Mediterranean diet is associated with a better health-related quality of life: a possible role of high dietary antioxidant content. BMJ Open. 2013;3:8.

36. Galilea-Zabalza I, Buil-Cosiales P, Salas-Salvado J, Toledo E, OrtegaAzorin C, Diez-Espino J, et al. Mediterranean diet and quality of life: Baseline cross-sectional analysis of the PREDIMED-PLUS trial. PLOS ONE. 2018;13(6):e0198974.

37. Farhangi MA, Najafi M, Jafarabadi MA, Jahangiry L. Mediterranean dietary quality index and dietary phytochemical index among patients candidate for coronary artery bypass grafting (CABG) surgery. BMC Cardiovasc Disor. 2017;17(1):114.

38. Panagiotakos DB, Pitsavos C, Stefanadis C. Dietary patterns: a Mediterranean diet score and its relation to clinical and biological markers of cardiovascular disease risk. Nutr Metab Cardiovasc Dis. 2006;16(8):559-68.

39. Rees K, Hartley L, Flowers N, Clarke A, Hooper L, Thorogood M, et al. 'Mediterranean' dietary pattern for the primary prevention of cardiovascular disease. Cochrane Database Syst Rev. 2013;8:Cd009825.

40. Farhangi MA, Ataie-Jafari A, Najafi M, Foroushani GS, Tehrani MM, Jahangiry L. Gender differences in major dietary patterns and their relationship with cardio-metabolic risk factors in a year before coronary artery bypass grafting (CABG) surgery period. Arch Iran Med. 2016;19(7):470-9.

41. Boucher JL. Mediterranean eating pattern. Diabetes Spectr. 2017:30(2):72-6.

42. Wells G, Shea B, O'connell D, Peterson J, Welch V, Losos M, et al. The Newcastle-Ottawa Scale (NOS) forassessing the quality of nonrandomised studies in meta-analyses. https://www.ohri.ca/programs/clini cal_epidemiology/oxford.asp. Accessed 18 Dec 2018
43. Moher D, Shamseer L, Clarke M, Ghersi D, Liberati A, Petticrew M, et al. Preferred reporting items for systematic review and meta-analysis protocols (PRISMA-P) 2015 statement. Syst Rev. 2015;4(1):1.

44. Sanchez-Aguadero N, Alonso-Dominguez R, Garcia-Ortiz L, AgudoConde C, Rodriguez-Martin C, de Cabo-Laso A, et al. Diet and physical activity in people with intermediate cardiovascular risk and their relationship with the health-related quality of life: results from the MARK study. Health Qual Life Outcomes. 2016;14(1):169.

45. Zaragoza-Marti A, Ferrer-Cascales R, Hurtado-Sanchez JA, Laguna-Perez A, Cabanero-Martinez MJ. Relationship between adherence to the mediterranean diet and health-related quality of life and life satisfaction among older adults. J Nutr Health Aging. 2018;22(1):89-96.

46. Milte CM, Thorpe MG, Crawford D, Ball K, McNaughton SA. Associations of diet quality with health-related quality of life in older Australian men and women. Exp Gerontol. 2015;64:8-16.

47. Moravejolahkami AR, Paknahad Z, Chitsaz A. Association of dietary patterns with systemic inflammation, quality of life, disease severity, relapse rate, severity of fatigue and anthropometric measurements in MS patients. Nutr Neurosci. 2019;21:1-11.

48. Trichopoulou A, Kouris-Blazos A, Wahlqvist ML, Gnardellis C, Lagiou P, Polychronopoulos E, et al. Diet and overall survival in elderly people. BMJ. 1995;311(7018):1457-60.

49. Arisawa K, Uemura H, Yamaguchi M, Nakamoto M, Hiyoshi M, Sawachika F, et al. Associations of dietary patterns with metabolic syndrome and insulin resistance: a cross-sectional study in a Japanese population. J Med Investig. 2014;61(3-4):333-44.

50. Mertens E, Markey O, Geleijnse JM, Givens DI, Lovegrove JA. Dietary patterns in relation to cardiovascular disease incidence and risk markers in a middle-aged british male population: data from the caerphilly prospective study. Nutrients. 2017;9(1):75.

51. Lopez-Garcia E, Schulze MB, Fung TT, Meigs JB, Rifai N, Manson JE, et al. Major dietary patterns are related to plasma concentrations of markers of inflammation and endothelial dysfunction. Am J Clin Nutr. 2004;80(4):1029-35.

52. Nasir Y, Rahimi M-H, Molahosseini M, Yekaninejad S, Maghbooli Z, Mirzaei K. The association of major dietary patterns with depression, anxiety and stress in apparently healthy adults. J Nutr Sci Diet. 2016;2:1-14.

53. Paskulin JT, Drehmer M, Olinto MT, Hoffmann JF, Pinheiro AP, Schmidt Ml, et al. Association between dietary patterns and mental disorders in pregnant women in Southern Brazil. Braz J Psychiatry. 2017;39(3):208-15.

54. Kim J, Yu A, Choi BY, Nam JH, Kim MK, Oh DH, et al. Dietary patterns and cognitive function in Korean older adults. Eur J Nutr. 2015;54(2):309-18.

55. Castren E, Berninger B, Leingartner A, Lindholm D. Regulation of brainderived neurotrophic factor mRNA levels in hippocampus by neuronal activity. Prog Brain Res. 1998;117:57-64.

56. Molteni R, Barnard RJ, Ying Z, Roberts CK, Gomez-Pinilla F. A high-fat, refined sugar diet reduces hippocampal brain-derived neurotrophic factor, neuronal plasticity, and learning. Neuroscience. 2002;112(4):803-14.

57. Dontas AS, Zerefos NS, Panagiotakos DB, Vlachou C, Valis DA. Mediterranean diet and prevention of coronary heart disease in the elderly. Clin Interv Aging. 2007;2(1):109-15.

58. Shikany JM, Safford MM, Bryan J, Newby PK, Richman JS, Durant RW, et al. Dietary Patterns and Mediterranean Diet Score and Hazard of Recurrent Coronary Heart Disease Events and All-Cause Mortality in the REGARDS Study. J Am Heart Assoc. 2018;7:14.

59. Kastorini CM, Milionis HJ, Esposito K, Giugliano D, Goudevenos JA, Panagiotakos DB. The effect of Mediterranean diet on metabolic syndrome and its components: a meta-analysis of 50 studies and 534,906 individuals. J Am Coll Cardiol. 2011;57(11):1299-313.

60. Salas-Salvado J, Bullo M, Babio N, Martinez-Gonzalez MA, Ibarrola-Jurado $\mathrm{N}$, Basora J, et al. Reduction in the incidence of type 2 diabetes with the Mediterranean diet: results of the PREDIMED-Reus nutrition intervention randomized trial. Diabetes Care. 2011:34(1):14-9.

61. Sanchez-Villegas A, Henriquez P, Bes-Rastrollo M, Doreste J. Mediterranean diet and depression. Public Health Nutr. 2006;9(8a):1104-9.

62. Lourida I, Soni M, Thompson-Coon J, Purandare N, Lang IA, Ukoumunne $\mathrm{OC}$, et al. Mediterranean diet, cognitive function, and dementia: a systematic review. Epidemiology. 2013;24(4):479-89. 
63. Psaltopoulou T, Sergentanis TN, Panagiotakos DB, Sergentanis IN, Kosti R, Scarmeas N. Mediterranean diet, stroke, cognitive impairment, and depression: a meta-analysis. Ann Neurol. 2013;74(4):580-91.

64. Gong XH, Wang JW, Li J, Chen XF, Sun L, Yuan ZP, et al. Physical exercise, vegetable and fruit intake and health-related quality of life in Chinese breast cancer survivors: a cross sectional study. Qual Life Res. 2017:26(6):1541-50

65. Bjornara HB, Overby NC, Stea TH, Torstveit MK, Hillesund ER, Andersen LF, et al. The association between adherence to the New Nordic Diet and diet quality. Food Nutr Res. 2016;60(1):31017.

66. Jensen TM, Braaten T, Jacobsen BK, Barnung RB, Olsen A, Skeie G. Adherence to the Healthy Nordic Food Index in the Norwegian Women and Cancer (NOWAC) cohort. Food Nutr Res. 2018;62:1339.

67. Calder PC. Very long-chain n-3 fatty acids and human health: Fact, fiction and the future. Proc Nutr Soc. 2017;17(1):52-72.
68. Kant AK. Dietary patterns and health outcomes. J Am Diet Assoc. 2004;104(4):615-35

\section{Publisher's Note}

Springer Nature remains neutral with regard to jurisdictional claims in published maps and institutional affiliations.
Ready to submit your research? Choose BMC and benefit from:

- fast, convenient online submission

- thorough peer review by experienced researchers in your field

- rapid publication on acceptance

- support for research data, including large and complex data types

- gold Open Access which fosters wider collaboration and increased citations

- maximum visibility for your research: over $100 \mathrm{M}$ website views per year

At BMC, research is always in progress.

Learn more biomedcentral.com/submissions 